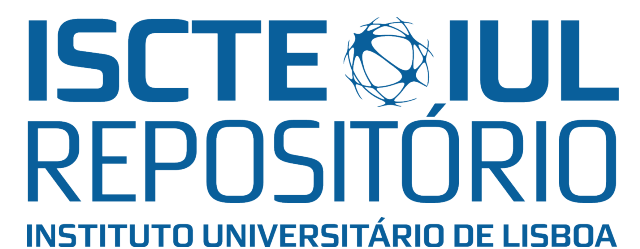

Repositório ISCTE-IUL

Deposited in Repositório ISCTE-IUL:

2021-01-27

Deposited version:

Accepted Version

Peer-review status of attached file:

Peer-reviewed

Citation for published item:

Camilo, C., Garrido, M. V. \& Calheiros, M. M. (2020). Recognizing children's emotions in child abuse and neglect. Aggressive Behavior. N/A

Further information on publisher's website:

10.1002/ab.21935

Publisher's copyright statement:

This is the peer reviewed version of the following article: Camilo, C., Garrido, M. V. \& Calheiros, M. M. (2020). Recognizing children's emotions in child abuse and neglect. Aggressive Behavior. N/A, which has been published in final form at https://dx.doi.org/10.1002/ab.21935. This article may be used for non-commercial purposes in accordance with the Publisher's Terms and Conditions for self-archiving.

Use policy

Creative Commons CC BY 4.0

The full-text may be used and/or reproduced, and given to third parties in any format or medium, without prior permission or charge, for personal research or study, educational, or not-for-profit purposes provided that:

- a full bibliographic reference is made to the original source

- a link is made to the metadata record in the Repository

- the full-text is not changed in any way

The full-text must not be sold in any format or medium without the formal permission of the copyright holders. 


\title{
Recognizing children's emotions in child abuse and neglect
}

\author{
Cláudia Camilo \\ Iscte-Instituto Universitário de Lisboa, Cis_Iscte, Lisboa, Portugal \\ claudia_sofia_camilo@iscte-iul.pt \\ Margarida Vaz Garrido \\ Iscte-Instituto Universitário de Lisboa, Cis_Iscte, Lisboa, Portugal \\ margarida.garrido@iscte-iul.pt \\ Maria Manuela Calheiros \\ CICPSI, Faculdade de Psicologia, Universidade de Lisboa, Lisboa, Portugal \\ Iscte-Instituto Universitário de Lisboa, Cis_Iscte, Lisboa, Portugal \\ maria.calheiros@psicologia.ulisboa.pt
}

Corresponding author: Cláudia Camilo, Cis_Iscte, Avenida das Forças Armadas, Edifício

Iscte-IUL, 1649-026, Lisboa, Portugal. Email: claudia_sofia_camilo@iscte-iul.pt; Phone number: 00351217903000.

Declarations of interest: none

Funding: This work was supported by the Portuguese Foundation for Science and Technology with grants awarded to the first [SFRH/BD/99875/2014] and second [PTDC/MHC-PCN/5217/2014] authors.

Data availability statement: The data that support the findings of this study are available from the corresponding author upon reasonable request. 
This is the author's version of a work that was accepted for publication in Aggressive Behavior. Changes resulting from the publishing process, such as peer review, editing, corrections, structural formatting, and other quality control mechanisms may not be reflected in this document. Changes may have been made to this work since it was submitted for publication. A definitive version was subsequently published as: Camilo, C., Garrido, M. V., \& Calheiros, M. M. (2020). Recognizing children's emotions in child abuse and neglect. Aggressive Behavior. doi:10.1002/ab.21935 


\begin{abstract}
Past research has suggested that parents' ability to recognize their children's emotions is associated with an enhanced quality of parent-child interactions and appropriateness of parental caregiving behavior. Although this association has also been examined in abusive and neglectful parents, the results are mixed and do not adequately address child neglect. Based on the Social Information Processing model of child abuse and neglect, we examined the association between mothers' ability to recognize children's emotions and self- and professionals-reported child abuse and neglect. The ability to recognize children's emotions was assessed with an implicit valence classification task and an emotion labeling task. A convenience sample of 166 mothers (78 with at least one child referred to Child Protection Services) completed the tasks. Child abuse and neglect were measured with self-report and professionals-report instruments. The moderating role of mothers' intellectual functioning and socioeconomic status were also examined. Results revealed that abusive mothers performed more poorly on the negative emotions recognition task, while neglectful mothers demonstrated a lower overall ability in recognizing children's emotions. When classifying the valence of emotions, mothers who obtained higher scores on child neglect presented a higher positivity bias particularly when their scores in measures of intellectual functioning were low. There was no moderation effect for socioeconomic status. Moreover, the results for child abuse were mainly observed with self-report measures, while for child neglect, they predominantly emerged with professionals-report. Our findings highlight the important contribution of the SIP model in the context of child maltreatment, with implications for prevention and intervention addressed.
\end{abstract}

Keywords: child abuse and neglect; maladaptive parenting; emotion recognition; attentional processes 
EMOTION RECOGNITION IN CHILD ABUSE AND NEGLECT

\section{Recognizing children's emotions in child abuse and neglect}

Children's positive and negative emotions are communicated to caregivers in different ways, such as vocalizations, gestures, body postures, body movements, and facial expressions (Halberstadt et al., 2013). Emotion recognition accuracy has been considered a fundamental skill in the development of empathic responses and well-adapted behavior (e.g., Besel \& Yuille, 2010). Specifically, in the case of children, facial expressions not only inform about the child's emotional state, but also evoke behavioral motives in the caregivers (for a review, see Aradhye et al., 2015).

Parents' recognition of children facial expressions has been a focus of interest in the child maltreatment literature, in which the association between parents' ability to recognize facial expressions and maladaptive parental practices has been explored (e.g., Camilo et al., 2020a; Hildyard \& Wolfe, 2007; Wagner et al., 2015). Based in a Social Information Processing (SIP) model of child abuse and neglect (Crittenden, 1993; Milner, 2003), we further examined abusive and neglectful mothers' ability in recognizing children's emotions using implicit and explicit measures.

Even though the literature on parents' perception of children facial expressions has received little attention (Bolzani-Dinehart et al., 2005; Braungart-Rieker et al., 2001), parental sensitivity to infant emotions' expression has been identified as an important predictor of the quality of parent-child interactions (Mesman et al., 2012; Murray et al., 2010). Indeed, the smiling and crying of a child communicating his/her emotional state have been shown to trigger caretaking mechanisms even when the adults have no previous relationship with the child (Aradhye et al., 2015). Research also indicates that adults are generally responsive to children's facial cues and expressions (Sprengelmeyer et al., 2009) and the neurobiology of parental sensitivity suggests that specific brain regions implicated in emotion perception, response, and regulation are activated in response to children's visual 


\section{EMOTION RECOGNITION IN CHILD ABUSE AND NEGLECT}

stimuli (e.g., Swain, 2011). Other studies indicate that maternal sensitivity is correlated with more attentional resources engaged in children's emotional face processing (Bernard et al., 2015). Moreover, emotion recognition ability is likely to be impaired in cases of maternal depression (Arteche et al., 2011) and borderline personality disorder (Elliot et al., 2014). For example, some studies indicated that people with depression are more attentive to negative faces and recognize ambiguous faces as less happy (Webb \& Ayers, 2014). Also, mothers with posttraumatic stress disorder present more difficulties in emotions' processing, with the type of trauma exposure influencing the emotional perception of infant's signals (Webb \& Ayers, 2014).

Socio-cognitive approaches to maladaptive parenting have emphasized the importance of parents' perception of child cues, signals or states, such as the recognition of children's emotions. The SIP model on child maltreatment suggests that abusive and neglectful parents present biases in perceiving and interpreting their children's signals during parent-child interactions. Specifically, children's signals are perceived and encoded through attentional processes, involving selective attention and encoding of child-related information, and filtered by parents' preexisting cognitive schemata about caregiving. The potential biases involved in these processes influence the way they integrate information about the event, select a parental response, and behave towards the child (Crittenden, 1993; Milner, 1993, 2003). Recent research about the SIP model applied to child physical abuse and neglect suggests that abusive and neglectful parents are more likely to hold inaccurate and biased preexisting cognitive schemata such as an external locus of control (e.g., Rodriguez, 2010) and higher negative affect towards children (e.g., Pérez-Albéniz \& de Paúl, 2006), present more difficulties in perceiving children's signals such as children's emotions (e.g., Francis \& Wolfe, 2008), make more biased attributions about children's behavior, interpreting this behavior as more negative and as more wrong (e.g., Rodriguez \& Tucker, 2015), and present 


\section{EMOTION RECOGNITION IN CHILD ABUSE AND NEGLECT}

more difficulties in the integration of child-related information and response selection, revealing difficulties in problem-solving (e.g., Azar et al., 2016) and a limited repertoire of adequate parenting techniques (e.g., Rodriguez et al., 2016).

The literature has also advanced different hypotheses regarding emotional recognition abilities in the context of child abuse and neglect. The SIP model applied to child abuse (Milner, 1993, 2003) states that abusive parents are less attentive and aware of their children's behavior than non-abusive parents and are more likely to observe more noncompliant child behavior. Further, these parents are less accurate in encoding childrelated information, make more errors in recognizing children's emotional expressions, namely low intense emotions, and tend to incorrectly evaluate the intensity of emotions. Such biases are believed to occur due to attentional differences occurring when parents are experiencing stress, resulting in a higher focus on negative stimuli (Milner, 2000). Moreover, research on aggression suggests that aggressive individuals, such as abusive parents, present a negativity bias in their attentional processes namely towards negative stimuli such as negative facial expressions or negative behavior (e.g., Larkin et al., 2002). Research regarding child abuse has focused on emotion recognition errors (e.g., Balge \& Milner, 2000) and biases in perceiving children's behavior (e.g., likelihood to observe noncompliant child behavior) (e.g., Rodriguez, 2018). Specifically, in the context of emotion recognition, a few studies have reported that abusive and high-risk of child physical abuse parents showed more errors in recognizing specific emotional expressions (Asla et al., 2011; Kropp \& Haynes, 1987) and labeled ambiguous children's emotions more often as negative (Francis \& Wolfe, 2008), when compared to non-abusive and low-risk parents. However, other studies have found no significant differences in recognizing children emotional expressions between high and low risk parents (Balge \& Milner, 2000; Wagner et al., 2015), and abusive and non-abusive mothers (Camras et al., 1988). Despite these inconsistencies, meta-analytic data revealed that, 


\section{EMOTION RECOGNITION IN CHILD ABUSE AND NEGLECT}

overall, high-risk and abusive parents exhibit significantly lower emotion recognition accuracy (Wagner et al., 2015).

In the context of child neglect, the SIP model suggests that neglectful parents fail to perceive their children's signals due to psychological states of withdraw and depression, and even due to cognitive deficits that can sometimes be associated with neglectful parenting (e.g., Azar et al., 2017; Crittenden, 1993). Although there are few studies applying the SIP model to child neglect (e.g., Camilo et al., 2020b), Hildyard and Wolfe (2007) found that neglectful mothers tend to present more difficulties in recognizing children emotions, compared with non-neglectful mothers. Moreover, neglectful mothers were more likely to label infants' facial expressions as negative emotions (e.g., shame, sadness) and their emotion vocabulary seemed less developed (Hildyard \& Wolfe, 2007). These findings suggest that the psychological characteristics associated with neglectful parenting may impede parents from displaying lively affective involvement with their children, failing to interact with them, and to notice interpersonal signals (e.g., child crying or requesting attention) and contextual needs (e.g., time since the last meal) of their children. Neglectful parents are likely to preconsciously exclude from cognitive perception information that elicits affect, reducing their flexibility to respond to environmental demands (Crittenden, 1993). Research on maternal representations of attachment has also explored parents' emotion recognition capabilities, providing further support for their association with child neglect. For example, dismissing mothers are more likely to label infants" emotions in a simplistic "black or white" manner, and are less open and responsive to negative affect. These findings suggest that child neglect is possibly associated with a "defensive exclusion" strategy toward negative emotional information (DeOliveira et al., 2005), which is likely to be related to parents' past trauma and loss (Éthier et al., 2004). Specifically, toxic stress responses to traumatic experiences has potential impacts on parents' socio-emotional development during their 


\section{EMOTION RECOGNITION IN CHILD ABUSE AND NEGLECT}

childhood, which influences their actual emotional processing (Bridgett et al., 2017; National Scientific Council on the Developing Child, 2012). Further, results from neuropsychological data (Bernard et al., 2015) suggest that the lack of maternal sensitivity, that often characterizes neglectful behavior, is associated with disruptions in attentional processes entangled in the processing of children's emotional cues. Alternative explanations propose that neglectful parents are less likely to experience empathy when exposed to children's signals of need, engaging in "empathy avoidance" in order to avoid the costs of helping that are likely to be incurred when one experiences empathy (De Paul \& Guibert, 2008).

Problems in recognizing emotions from facial expressions are also associated with general cognitive skills and executive functions. Research conducted with children with cognitive disabilities has shown that these children have underdeveloped emotion recognition skills. Specifically, they tend to encode less emotional information from the social interaction situation, which in turn impairs their interpretation skills and adequacy of response selection and implementation (Van Nieuwenhuijzen \& Vriens, 2012). Results from studies conducted with adults demonstrated that intellectual functioning predicted the ability to label emotional faces (Jahoda et al., 2006). In parallel, poverty-related adversity has been associated with impoverished emotion labeling ability (e.g., Erhart et al., 2019; Raver et al., 2015). Studies examining the relation between poverty and related contextual risks such as neighborhood violence or parental stress, and emotion labeling in adults are scarce. However, research on parental sensitivity (which is associated with emotion perception) showed that parents exposed to poverty present a reduced parental sensitivity (Pinderhughes et al., 2007).

Regarding the measures used in emotion recognition studies, research on child abuse and neglect has been evaluating the two major components of emotional expressions: the explicit prototypical emotion recognition in categorization tasks (labeling of facial expressions) and measures of implicit affect toward facial expressions, namely valence and 


\section{EMOTION RECOGNITION IN CHILD ABUSE AND NEGLECT}

arousal (Calvo \& Nummenmaa, 2016; for a review see Camilo et al., 2016). The categorical approach has mainly been considering the six basic emotional expressions (happiness, anger, sadness, fear, disgust, and surprise; Ekman \& Friesen, 1978) and its application to the study of abusive and neglectful parenting has been predominantly conducted using the Facial Action Coding System (e.g., During \& McMahon, 1991), the IFEEL Pictures lexicon clusters (e.g., Francis \& Wolfe, 2008), or the DANVA II (e.g., Asla et al., 2011). Studies involving the measurement of implicit affect are scarce and have been based on affective priming paradigms to evaluate emotional valence (e.g., Wagner et al., 2015). Specifically, in terms of reaction times, the automaticity that characterizes the recognition process of facial expressions of emotions is well established (e.g., Bargh, 1994; Tracy \& Robins, 2008). Daily social interactions enforce processing demands resulting from the flow of quickly changing affective information, often under distractive conditions (Halberstadt et al., 2009). And although it is known that emotions processing is influenced by the context (e.g., Aviezer et al., 2011), reaction times in recognizing emotions have been used in lab tasks to assess the speed of basic attentional processes, identifying potential attentional bias by simulating one's immediate environment, namely in the context of parenting (e.g., Camilo et al., 2016).

Considering the inconsistent results found in the literature on emotion recognition in the context of child abuse and neglect (Wagner et al., 2015), as well as the lack of studies comparing abusive and neglectful parents, we deigned the present study to examine mothers' ability to recognize children's emotions as a function of their self and professionals-reported child abuse and neglect scores. To this end, two different tasks were developed: an implicit valence classification task, evaluating mothers' accuracy and response latencies in classifying the valence of children's emotional expressions as positive or negative, and a categorization task, to assess mothers' ability in labeling children's basic emotions. Based on the SIP model (Crittenden, 1993; Milner, 2003), we expected that mothers with higher child abuse scores (a) 


\section{EMOTION RECOGNITION IN CHILD ABUSE AND NEGLECT}

would be less accurate and slower in classifying positive than negative emotions in the implicit valence classification task, (b) would be less accurate in labeling positive than negative emotions, in the categorization task, and (c) would label ambiguous emotional faces more often as negative in both tasks. Mothers with higher child neglect scores were expected to present (a) lower accuracy and slower responses in classifying the valence of children's emotions (positive and negative emotions), in the implicit valence classification task and (b) a lower general ability in labeling specific emotions in children in the categorization task. We also expected them to label ambiguous faces more often as negative in both tasks. Moreover, it was expected that these effects would be stronger in mothers with low intellectual functioning and low socioeconomic status. Finally, we were interested in exploring the convergence of the results depending on the self- and professionals-report nature of the measures of child abuse and neglect used.

\section{Method}

\section{Participants}

A convenience sample of 166 Portuguese mothers participated in this study. Their ages ranged from 24 to 53 years old $(M=38.60, S D=6.39)$, and they had between 1 and 8 children $(M=2.63, S D=1.41)$. Most of the mothers were White $(70.5 \%)$ and did not complete high school (54.2\%). Approximately half of the sample $(\mathrm{n}=78)$ had at least one child referred to Child Protection Services (CPS). The remaining ( $n=88)$ were recruited in schools and community services from socially vulnerable communities, to balance the sociodemographic characteristics of the sample. Mothers were eligible for participation if they had at least one child within the age range of 5-13 years old $(M=9.50, S D=2.04)$ living with the family. Exclusion criteria included mothers with severe cognitive disabilities and lack of native language proficiency, given the cognitively demanding nature of the tasks included in the protocol. Finally, for the referred group, and in line with previous studies (e.g., Hildyard 


\section{EMOTION RECOGNITION IN CHILD ABUSE AND NEGLECT}

$\&$ Wolfe, 2007), mothers with a substantiated record of child sexual abuse as a perpetrator were not included.

\section{Measures}

Given the lack of validated measures of child abuse and neglect in the Portuguese context, we translated, adapted and validated two well-established parental self-report measures. Further, in order to obtain separate scores of child abuse and child neglect reported from professionals, a confirmatory analysis was conducted with a previous measure of professionals' report of child maltreatment validated for the Portuguese context.

Professionals' report of Child Abuse and Neglect. These reports were obtained through the Maltreatment Severity Questionnaire (MSQ; Calheiros et al., 2019), consisting of 21 items (e.g., Physical hygiene and wellbeing), each composed by four severity descriptors (e.g., from 1 = "They keep the child looking dirty (e.g., does not take a bath, does not wash her head or teeth, stinks, has parasites and/or fleas)" to $4=$ "They let the child have health problems or injuries due to her hygienic conditions (e.g., skin diseases, infected skin injuries"). Originally, the MSQ was organized as a three-factor structure: Physical neglect, Psychological neglect, and Physical and psychological abuse. In the current study, we obtained two separate global scores of child abuse and neglect $\left[\chi^{2}(129)=387.567, p<.001\right.$, $\chi^{2} / \mathrm{df}=3.004 ;$ comparative fit index $(\mathrm{CFI})=.815$; and root mean square error of approximation $(\mathrm{RMSEA})=.101]$ with good internal consistency indicators: Physical and Psychological neglect (14 items; $\alpha=.87$ ) and Physical and Psychological abuse (4 items; $\alpha=$ .71). Higher scores in the MSQ dimensions mean higher levels of child maltreatment. The MSQ was completed with the information available regarding each target-child, by CPS caseworkers (for the referred group of mothers) and by the child's teacher/ professional of community service (for the non-referred group). 
EMOTION RECOGNITION IN CHILD ABUSE AND NEGLECT

Self-reported Child Abuse. The Conflict Tactics Scale - Parent to Child (Straus et al., 1998 ) is a self-report measure that obtains reports of child abuse from parents. The questionnaire with 22 items (e.g., "Spanked him/her on the bottom with your bare hand") is originally organized in three main dimensions: Non-violent discipline, Psychological aggression, and Physical assault (the latter, composed by Corporal punishment, Physical maltreatment, and Extreme physical maltreatment). Mothers rated statements on a 7-point scale ranging from $0=$ never happened to $7=$ more than 20 times in the past year. In the current study, an abuse scale was used, constituted by the dimensions of Psychological aggression and Corporal punishment $\left[\chi^{2}(39)=79.198, p<.001, \chi^{2} / \mathrm{df}=2.031\right.$; comparative fit index $(\mathrm{CFI})=.907$; and root mean square error of approximation $($ RMSEA $)=.067]$. This scale included 7 items $(\alpha=.72)$, with higher scores meaning higher child abuse.

Self-reported Child Neglect. The Multidimensional Neglectful Behavior ScaleParent Report (MNBS; Kantor et al., 2003) is a self-report measure that obtains reports of child neglect from parents with children aged between 5-15 years old. A previous version of the MNBS validated for a Portuguese sample (face validity; Neves \& Lopes, 2013) was used, composed by 49 items (e.g., "Did not know where your child was playing when she/he was outdoors"), divided in four core dimensions: Emotional neglect, Cognitive neglect, Supervision neglect, and Physical neglect. Respondents were asked about their parental behavior in a 4-point scale, ranging from $1=$ never to $4=$ always, in two different versions according to the age of the child (5 to 9 years old including the 49 items; 10 to 13 years old including 47 items). In the current study, a global score of child neglect was used $\left[\chi^{2}(346)=\right.$ $573.744, p<.001, \chi^{2} / \mathrm{df}=1.658$; comparative fit index $(\mathrm{CFI})=.926$; and root mean square error of approximation $(\mathrm{RMSEA})=.057]$, revealing good internal consistency $(\alpha=.83)$, with higher scores meaning higher child neglect. 
EMOTION RECOGNITION IN CHILD ABUSE AND NEGLECT

Valence of children's emotions. A speed-accuracy task was developed to indirectly measure how mothers recognize the valence of children's emotional expressions. This task was adapted from a previous study about emotion recognition ability in individuals at highrisk of child physical abuse (Wagner et al., 2015). The pictures of children's facial emotions used in the present study were taken from the Child Affective Facial Expression set (CAFE; LoBue \& Thrasher, 2015) and validated for the Portuguese context by Prada and colleagues (2018). Sixty child frontal photographs: twenty models (ten boys and ten girls), posing in three different facial expressions (happiness, sadness and neutral) were presented twice (counterbalanced block order). The photographs were selected based on accuracy and valence scores (see Prada et al., 2018). Participants were asked to classify the emotions displayed (presented randomly within each block) as positive or negative, using two response keys (counterbalanced). Each of the two blocks consisted of a fixation point (250 ms), followed by the presentation of the child's photograph, and the classification task as "Positive" (left key in the first block; right key in the second block) or as "Negative" (right key in the first block; left key in the second block). Each experimental block was preceded by a practice block with five practice trials, in which participants classified randomly presented emojis displaying happiness, sadness, or neutral emotions, as positive or negative. The stimuli remained on the screen until the participants responded. In the practice trials, if participants failed to respond within $600 \mathrm{~ms}$, a reminder to "Please respond more quickly!" appeared. Accuracy and response times were collected.

Labeling of children's emotions. A forced-choice task was developed to directly measure mothers' accuracy in labeling children's facial expressions. Forty child frontal photographs were selected form the Child Affective Facial Expression set (CAFE; LoBue \& Thrasher, 2015; Prada et al., 2018): eight models (four boys and four girls), posing in five different facial expressions (happiness, sadness, fear, anger and neutral) were randomly 
presented. The photographs were selected based on labeling accuracy scores (see Prada et al., 2018). Participants were asked to identify the facial expression presented by the model by selecting the corresponding label (i.e., sadness, happiness, anger, fear, or neutral) that was displayed on the screen, below the photo.

Family socioeconomic status. Mothers were asked to report their highest completed education level, monthly family income, income source, housing and neighborhood characteristics, on a 5-point scale. Since all variables were positively and significantly correlated (all $p$ 's $<.01$ ), the scores were computed into an index of socioeconomic status (SES; $\alpha=.77$ ) (e.g., Beckerman et al., 2018). Lower scores indicated lower SES.

Mothers' intellectual functioning. Four subtests of the WAIS-III (Arithmetic, Matrix reasoning, Information, Coding; $\alpha=.62$; Wechsler, 1997; Portuguese version of CEGOC, 2008) were used as an estimate of general intellectual functioning due to their previously reported high correlation with the full scale (e.g., Azar et al., 2017). The subtests were administered in order and according to the standardized procedures outlined in the respective manual.

\section{Procedure}

The data used in the current paper represent a selection of the measures collected in the context of a more comprehensive research program. All measures and procedures were approved by the Ethics Committee of the host institution (EA\# 08/2016).

After obtaining the permission from the institutions (12 CPS agencies, 8 schools, and 9 community institutions), mothers who met the inclusion criteria were contacted by the CPS, community services and schools, and were invited to participate in a study about parenting. Those who agreed to participate were invited for two individual sessions taking place at the respective CPS agencies (referred group), schools and community services (non-referred group). Participants were further informed that they would participate in a study examining 
how mothers perceive, think, and remember information about child rearing and development, and their influence on parental practices.

In the first session, after reading and signing the informed consent, participants were asked to provide demographic information. Then they completed the implicit valence classification task and the emotions' labeling task, using E-Prime 2.0 in a laptop provided by the researcher. In the second session, the WAIS subtests, the MNBS and the CTS-PC were administered ${ }^{1}$. After completing both sessions, participants were thanked, debriefed and compensated with a $10 €$ gift card. Later, the MSQ was completed by the CPS caseworkers or by the child's teacher/ community service professional.

\section{Data analysis strategy}

SPSS 25.0 was used to conduct data-analysis. The independent variables were standardized, and analysis of normal distribution and potential outliers revealed the absence of standardized scores lower than -3.29 or higher than 3.29 (Tabachnick \& Fidell, 2012), except for abuse dimension of MSQ. Moreover, since the absolute value of skewness of this dimension was higher than 3 (Kline, 2005), the highest three values were eliminated, and normality was reached.

To test our hypotheses, the relations between child abuse/neglect and emotion recognition was explored by means of the General Linear Model (GLM). Specifically, our independent variables were self-reported child abuse and neglect, and professionals-reported child abuse and neglect (since no significant correlations were found between self and professionals-reports; see Table 1). The dependent variables were: a) accuracy and response latency of correct responses and b) valence (positive or negative) attributed to ambiguous

\footnotetext{
${ }^{1}$ According to the Portuguese law (Lei n. ${ }^{\circ}$ 147/99, de 01 de Setembro), in case of abusive and/or neglectful behavior reported by non-referred mothers, or by the professionals regarding the non-referred cases, the research team had the duty of reporting these cases to the CPS system. In our study, the non-referred cases with higher scores of abuse and/or neglect were already identified by the welfare teams specialized in children at risk, with professionals already intervening with the families, as defined by the child protection Portuguese law.
} 


\section{EMOTION RECOGNITION IN CHILD ABUSE AND NEGLECT}

emotions in the implicit valence classification task; c) accuracy in labeling emotions, and d) labels (positive or negative) attributed to ambiguous emotions (neutral facial expressions) in the categorization task. Given the high co-occurrence of different types of maltreatment (Kim et al., 2017), both child abuse and neglect were included in the models. Moreover, we tested the moderation effect of mothers' general intellectual functioning and socioeconomic status (included as continuous variables) in the association of child abuse and neglect and emotion recognition.

Self-reports and professionals-reports of child abuse and neglect were analyzed as independent sources of information (e.g., Kaufman et al., 1994). Parents' reports of child abusive and neglectful behavior are potentially biased in that parents may report in a socially desirable manner, trying to minimize negative behavior or, less frequently, exaggerating their problems (Bennet et al., 2006).

\section{Results}

\section{Implicit valence classification task}

We started with data reduction (e.g., Bargh \& Chartrand, 2014). Participants with an accuracy rate lower than $50 \%$ were removed from the analysis, resulting in the exclusion of 8 participants (4.82\%). Responses with latencies lower than $350 \mathrm{~ms}$ and higher than $2500 \mathrm{~ms}$ were eliminated (3.18\%); subsequently, responses lower or higher than 2.5 standard deviation from the mean of each block were eliminated (6.37\%). After these procedures, participants with less than $50 \%$ of valid responses were excluded from analysis, resulting in the additional exclusion of 6 participants (rate of valid responses between $37.50 \%-48.75 \%$ ). In total 14 participants $(8.43 \%)$ were excluded from the analysis. Data from the practice blocks were discarded. 


\section{EMOTION RECOGNITION IN CHILD ABUSE AND NEGLECT}

Regarding the accuracy in classifying the valence of emotions, a main effect of stimulus type was observed, $F(1,147)=11.459, p=.001, \eta_{\mathrm{p}}{ }^{2}=.072$, such that happy faces $(M=37.25, S E=0.26)$ obtained higher accuracy than sad faces $(M=35.62, S E=0.42)$. The main effects of self-reported child abuse, $F(1,147)=1.892, p=.171$, and child neglect, $F(1$, $147)=2.916, p=.090$ were not statistically significant. However, significant interactions were found between stimulus type and child abuse, $F(1,147)=6.744, p=.010, \eta_{\mathrm{p}}{ }^{2}=.044$. Contrast analyses showed that mothers with higher scores on the child abuse scale were less accurate in classifying sad faces $(b=-1.00), t(147)=-2.311, p=.022, \eta_{\mathrm{p}}{ }^{2}=.035$, but not happy faces, $t(147)=1.108, p=.270$. When using professionals-reported child abuse and neglect, no significant main effects of child abuse, $F(1,147)=0.643, p=.424$, or child neglect, $F(1,147)=1.328, p=.251$, were observed, nor were interactions between stimulus type and child abuse and neglect (all $p$ 's $>.05$ ). None of the measures of child abuse and neglect were associated with the valence (positive or negative) attributed to neutral faces (all p's > .05).

For latency, the results also revealed a main effect of the stimulus type, $F(1,147)=$ $48.249, p<.001, \eta_{\mathrm{p}}{ }^{2}=.247$, with faster response latencies for happy faces $(M=837.58, S E=$ 11.97) than for sad faces $(M=908.52, S E=13.93)$. The main effects of self-reported child abuse $F(1,147)=1.798, p=.182$ and child neglect $F(1,147)=0.073, p=.788$ were not significant. However, the interaction between stimulus type and child abuse, $F(1,147)=$ $5.524, p=.020, \eta_{\mathrm{p}}^{2}=.036$, was significant. In line with the accuracy results, contrast analyses showed that mothers scoring higher on child abuse were slower at recognizing sad faces $(b=29.02), t(147)=2.014, p=.046, \eta_{\mathrm{p}}^{2}=.027$, but not happy faces, $t(147)=0.329, p$ $=.743$. Regarding professionals-reported child abuse and neglect, the results revealed a main effect of child neglect $(b=34.96), F(1,147)=5.321, p=.024, \eta_{\mathrm{p}}{ }^{2}=.034$, with higher child neglect scores being associated with higher latencies in classifying both positive and negative 


\section{EMOTION RECOGNITION IN CHILD ABUSE AND NEGLECT}

emotions as expected. The main effect of child abuse was not significant, $F(1,147)=0.409$, $p=.523$, and no significant interactions were found between stimulus type and child abuse and neglect (all $p$ 's $>.05)$.

In sum, the results from the implicit valence classification task indicate that mothers were overall more accurate and faster in recognizing positive than negative emotions. Notably, mothers scoring higher on self-reported child abuse were less accurate and slower at recognizing negative emotional expressions. In turn, mothers scoring higher on professionalsreported child neglect were overall slower in classifying both positive and negative facial expressions.

\section{Labeling children's emotions}

For the accuracy in labeling children's emotions, a main effect of stimulus type (happiness, sadness, fear, anger, neutral) was observed, $F(4,620)=69.674, p<.001, \eta_{\mathrm{p}}{ }^{2}=$ .310 , with happiness $(M=7.51, S E=0.08)$ obtaining the highest accuracy and fear $(M=$ 4.92, $S E=0.17)$ obtaining the lowest. The main effects of self-reported child abuse $F(1,155)$ $=0.701, p=.404$, and child neglect $F(1,155)=2.560, p=.112$, were not significant, nor were the interactions between stimulus type and child abuse and neglect (all $p$ 's $>.05$ ). However, a significant main effect of professionals-reported child neglect was observed $(b=$ -1.68), $F(1,155)=9.552, p=.002, \eta_{\mathrm{p}}^{2}=.058$, with higher child neglect scores associated with less accuracy in labeling children's emotions. No significant results were found for child abuse, $F(1,155)=0.831, p=.363$, neither significant interactions between stimulus type and child abuse and neglect (all $p$ 's $>.05$ ).

When labeling ambiguous emotions (neutral facial expressions), no significant effects were found for self-reported child abuse, $F(1,155)=0.070, p=.791$, or neglect, $F(1,155)=$ $0.049, p=.825$. Regarding professionals-reported child abuse and neglect, a main effect of child neglect was observed $(b=0.12), F(1,155)=6.469, p=.012, \eta_{\mathrm{p}}{ }^{2}=.040$, indicating that 
mothers with higher child neglect scores labeled ambiguous emotions more often as negative. No significant results were found for child abuse, $F(1,155)=0.715, p=.399$.

Overall, mothers were more accurate in classifying happy faces than negative faces. Mothers scoring higher on professionals-reported child neglect were less accurate in labeling children's emotions and labeled ambiguous facial expressions more often as negative emotions, while no significant effects were found for child abuse. No significant results were found for self-reported child abuse and neglect.

\section{The moderating role of mothers' general intellectual functioning and socioeconomic status}

In order to examine whether the relation between child abuse and neglect and mothers' emotion recognition capabilities differs according to their intellectual functioning and socioeconomic status, a set of moderation effects were tested. Only a moderation effect was found in the implicit valence classification task. Specifically, a significant interaction between mothers' intellectual functioning and self-reported child neglect was observed for response latencies $(b=-28.98), F(1,136)=3.971, p=.048, \eta_{\mathrm{p}}{ }^{2}=.028$. Mothers with higher scores on child neglect had a higher positivity bias (faster classification of positive than negative emotions) when they exhibit lower levels of intellectual functioning. Socioeconomic status did not moderate the associations between child abuse and neglect in any of the tasks.

\section{Discussion}

It has long been suggested that parents' ability to recognizing children's emotions is associated with an enhanced quality of parent-child interactions and appropriateness of parental caregiving behavior (e.g., Webb et al., 2019). Studies exploring parents' information processing in child maltreatment have examined whether abusive and neglectful parents are more likely to present bias in recognizing children's emotional states (e.g., Hildyard \& 
Wolfe, 2007; Wagner et al., 2015). However, these studies present mixed results (e.g., Wagner et al., 2015) and only a few have addressed child neglect (Hildyard \& Wolfe, 2007).

Based on the SIP model of child abuse and neglect, we used an implicit valence classification task and a labelling task to examine mothers' ability in recognizing children's emotions depending on their levels of self- and professionals-reported child abuse and neglect. The moderating role of mothers' intellectual functioning and socioeconomic status, as well as the convergence of the results depending on the type of reporter used (i.e., mothers or professionals) to assess child abuse and neglect were also explored.

The results indicated that mothers were overall faster and more accurate in classifying the valence of positive emotional expressions, as well as more competent in labeling positive than negative emotions. This result is in line with face-perception research conducted with the general population, which has been consistently demonstrating that happy facial expressions are more salient and subsequently easier to identify (e.g., Elfenbein \& Ambady, 2002). Specifically, happy faces are perceived as cues to pleasurable interaction and have important adaptive functions (Nummenmaa \& Calvo, 2015). Considering that child happy expressions are motivationally relevant stimuli to parents, evoking an approach response and motivating the parents to care for and nurture the child (for a review see Ferrey et al., 2016), it is an interesting result that this pattern still emerged in potentially maltreating samples.

Importantly, and contrary to our hypotheses, mothers scoring higher on child abuse were slower and less accurate at classifying the valence of children's emotional expressions when classifying sad faces. Although the literature has been suggesting that abusive parents have a negativity bias when recognizing children's emotions (e.g., Bauer \& Twentyman, 1985; Farc et al., 2008), our results suggest that abusive parents may present difficulties in perceiving children's facial expressions displaying negative emotions. This is an important result since the literature has identified difficulties in emotion recognition in aggressive 


\section{EMOTION RECOGNITION IN CHILD ABUSE AND NEGLECT}

individuals, but results regarding particular emotions have been inconclusive (García-Sancho et al., 2015). Our results suggest that when viewing negative emotions in others, namely those that motivate helping behavior such as sadness, abusive parents present difficulties in detecting these signals. This apparent difficulty in processing negative emotions might be related with impoverish empathy (Besel \& Yuille, 2010). Our results differ from studies that found the negativity bias in abusive parents probably because of the specific emotion presented. Indeed, previous studies presented negative stimuli such as anger and hostile emotions (e.g., Farc et al., 2008), while in our study, mothers were asked to classify sad faces. Thus, aggression in abusive parents may be primed by anger expressions, and not by sadness, which might readily prompt empathy and helping behavior. Since we did not contrast these different types of negative emotions (e.g., sadness vs. anger), nor did we assess variables such as empathy, future research is needed to directly disentangle these nuances.

Mothers scoring higher on child neglect were overall slower in classifying both positive and negative emotional expressions. These mothers were also less accurate in labeling children's emotions. Moreover, when labeling ambiguous facial expressions, mothers scoring higher on child neglect, labeled them more often as negative emotions, as expected. These results are in line with previous research with neglectful mothers, that reported more difficulties in recognizing children emotions, compared with non-neglectful mothers (Hildyard \& Wolfe, 2007). Neglectful parents are known to be under extreme psychological suffering (for a review see Stith et al., 2009), experiencing high levels of negative emotions. These experiences are thought to increase negative perceptions, and consequently, evaluations of children's behavior (e.g., Azar et al., 2012, 2017). Moreover, the SIP model applied to child neglect proposes that neglectful parents are likely to automatically exclude emotional information from cognitive perception, reducing their flexibility to respond to environmental demands (Crittenden, 1993), and to show less empathy toward others' 


\section{EMOTION RECOGNITION IN CHILD ABUSE AND NEGLECT}

emotional complexity (DeOliveira et al., 2005). Further, neglectful parents are more likely to have had adverse childhood experiences, such as extreme poverty, abuse and neglect (Mulder et al., 2018), with potential impacts in their socio-emotional development and consequences for their processing of emotional information. Moreover, research has been showing that dismissing mothers, such as neglectful mothers, are more likely to label infants' emotions in a simplistic "black or white" manner and are less open and responsive to negative affect, presenting a "defensive exclusion" strategy toward negative emotional information (DeOliveira et al., 2005). Alternative explanations from neuropsychological studies (e.g., Bernard et al., 2015) suggest that the lack of maternal sensitivity, that often characterizes neglectful behavior, is associated with disruptions in attentional processes entangled in the processing of children's emotional cues, which can potentially explain their overall difficulty in interpreting children's signals. However, further research on child neglect is required to confirm these assumptions. Still, we found a significant interaction between child neglect and intellectual functioning in the valence task, with more neglectful mothers having a higher positivity bias when also exhibiting lower levels of intellectual functioning. Specifically, when classifying the valence of emotions, these mothers were faster in recognizing positive emotional expressions than negative ones. However, this finding was only observed for selfreport and not for professionals-report, thus results from the moderation effect should be interpreted with caution.

The nature of abusive and neglectful parents' difficulties in recognizing children's emotions can also be related with the intergenerational transmission of child abuse and neglect. Indeed, abusive and neglectful parents are likely to have been, in their childhood, victims of maltreatment experiences (Stith et al., 2009), with impacts on their socioemotional development. The effects of these victimization processes may have decreased 


\section{EMOTION RECOGNITION IN CHILD ABUSE AND NEGLECT}

their ability to recognize emotions in others (Koizumi \& Takagishi, 2014), which is reflected in adulthood and in their parental role.

Regarding the consistency between self- and professionals reported measures of child maltreatment, the results for child abuse were found mainly with the self-reported measure, while results for child neglect predominantly emerged with the professionals-reported measure. A possible explanation for this difference is likely to rest on the different pathways of information processing in child abuse and neglect. Specifically, and although presenting bias and errors, abusive parents actually do process child-related information (Milner, 2003), which makes them probably more aware of their own behavior. In child neglect, the caregiving-related information processing is interrupted and not completed (Crittenden, 1993), and child neglect is often characterized by the absence of a parental response (contrary to child abuse where inadequate behavior emerges). Thus, it is more likely that neglectful parents do not have insights about their own behavior (e.g., Berthelot et al., 2015), as noted in the mixed results observed between self and professionals report of child neglect. Another possible interpretation for the lack of convergence between the results obtained across self and professionals-report measures is the fact that neglectful families, often characterized by poverty, psychological distress, and low educational levels, are more "visible" to professionals and services (being the most common form of maltreatment reported to CPS; Stoltenborgh et al., 2013). In turn, child abuse is only noted in its severe forms, when children suffer physical injuries and marks, making the less severe abusive interactions nonvisible to professionals, and therefore unreported (Gilbert et al., 2009). These results highlight the importance of having multiple sources of information in the assessment of child abuse and neglect (Kaufman et al., 1994).

Finally, and in contrast to our hypothesis, no moderation effects were found for socioeconomic status. Poverty has been associated with deficits in social information 


\section{EMOTION RECOGNITION IN CHILD ABUSE AND NEGLECT}

processing (Mani et al., 2013; Shah et al., 2012), and specifically, with lack of ability in emotion recognition (e.g., Erhart et al., 2019). Since the association of poverty with emotion recognition is mediated by stress (e.g., Daudelin-Peltier et al., 2017), the artificial context of the task might not have captured the influence of the contextual stressors in mothers' emotion recognition ability. Although previous studies (Asla et al., 2011; Balge \& Milner, 2000) already testing this hypothesis with high-risk of child physical abuse parents found inconsistent results, it would be important to further manipulate contextual factors in order to simulate real-world challenges, namely the presence of contextual stressors.

Despite some interesting findings, our study is not without limitations. First, we used static facial expressions instead of dynamic ones (Garrido et al., 2017), which would have been closer to natural parental contexts of caregiving, enhancing the mothers' sensitivity to children facial expressions (Branger et al., 2019). Further, facial expressions presented in the tasks were of unknown children. Although some studies with abusive samples reported no differences between parental perceptions of own versus other children (Dadds et al., 2003), others reported that maternal responses to facial emotions were different for their own child, compared to other child (Strathearn et al., 2008). Finally, considering previous research that suggests sex-differences in emotion recognition (e.g., Saylik et al., 2018), our sample was composed of only mothers, which precludes the possibility of comparisons with fathers. Future studies should address these limitations, namely considering the development of emotion recognition tasks with dynamic and familiar children, or complement these assessments with observational measures of parent-child interactions (Aspland \& Gardner, 2003). Further, given the importance of parental psychological states in emotion recognition (Arteche et al., 2011; Elliot et al., 2014), future research should consider the moderation effect of depression and hostility in parents' processing of emotions. Finally, considering the overall SIP model of child abuse and neglect, further research is still required to test the 


\section{EMOTION RECOGNITION IN CHILD ABUSE AND NEGLECT}

mediating role of parents' perception of child signals between parents' preexisting cognitive schemata (e.g., Camilo et al., 2019) and abusive and neglectful behavior.

Notwithstanding these limitations, our study is likely to entail important theoretical and methodological contributions to unravel the differences between abusive and neglectful parents in recognizing children's emotions. Our results highlight important implications for intervention in child maltreatment, namely by informing cognitive-behavioral programs with parents (Azar \& Wolfe, 2006; Chaffin et al., 2004) and community-based parenting interventions (Camilo \& Garrido, 2013). For example, interventions in emotion recognition abilities of abusive and neglectful parents could specifically target parents' meta-cognitive awareness and attentional focus management, emotion knowledge (Izard et al., 2008) and emotional competence (Kotsou et al., 2011). Specifically, grounded on assumptions of broader theories such as social cognitive theories, information processing models, and theories of learning, methods for behavior change such as repeated exposure (increasing the familiarity of a stimulus), counter conditioning (stimulus substitution, and available substitute behavior), implementation intentions (specific plan to promote the initiation and efficient execution of goal-directed activity), and environmental cues (forming new cue-response links) (e.g., Abraham et al., 1998; Petty et al., 2002) might also be implemented to increase parents' attentional focus management and to reduce the automaticity of their cognitions. Interventions such as empathy training (Feshbach \& Feshbach, 1982), mentalising and emotion recognition training, cuing selective/focused attention and Mentalisation-Based Therapy (Yeates, 2014), or attention control training such as mixed attention training, working memory training, and mindfulness meditation (Wass et al., 2012) might provide important inputs to successfully improve parents' emotion recognition capabilities. 


\section{References}

Abraham, C., Sheeran, P., \& Johnston, M. (1998). From health beliefs to self-regulation: theoretical advances in the psychology of action control. Psychology and Health, 13, 569-591. doi:10.1080/08870449808407420

Aradhye, C. Vonk, J., \& Arida, D. (2015). Adults' responsiveness to children's facial expressions. Journal of Experimental Child Psychology, 135, 56-71. doi:10.1016/j.jecp.2015.02.006.

Arteche, A., Joormann, J., Harvey, A., Craske, M., Gotlib, I. H., Lehtonen, A., ... Stein, A. (2011). The effects of postnatal maternal depression and anxiety on the processing of infant faces. Journal of Affective Disorders, 133, 197-203. doi:10.1016/j.jad.2011.04.015

Asla, N., De Paúl, J., \& Pérez-Albéniz, A. (2011). Emotion recognition in fathers and mothers at high-risk for child physical abuse. Child Abuse \& Neglect, 35, 712-721. doi:10.1016/j.chiabu.2011.05.010

Aspland, H. \& Gardner, F. (2003). Observational measures of parent-child interaction: An introductory review. Child and Adolescent Mental Health, 8, 136-143. doi:10.1111/1475-3588.00061

Aviezer, H., Bentin, S., Dudarev, V., \& Hassin, R. R. (2011). The automaticity of emotional face-context integration. Emotion, 11, 1406-1414. doi:10.1037/a0023578

Azar, S. T., \& Wolfe, D. (2006). Child physical abuse and neglect. In E. J. Mash \& R. A. Barkley (Eds.), Treatment of childhood disorders ( $3^{\text {rd }}$ ed., pp. 595-646). New York, NY: Guilford Press.

Azar, S. T., McGuier, D. J, Miller, E. A., Hernandez-Mekonnen, R., \& Johnson, D. R. (2017). Child neglect and maternal cross-relational social cognitive and neurocognitive disturbances. Journal of Family Psychology, 31, 8-18. doi:10.1037/fam0000268 
Azar, S. T., Miller, E. A., McGuier, D. J., Stevenson, M. T., O’Donnell, E., Olsen, N., \& Spence, N. (2016). Maternal social information processing and the frequency and severity of mother-perpetrated physical abuse. Child Maltreatment, 21, 308-316. doi:10.1177/1077559516668047

Azar, S. T., Reitz, E. B., \& Goslin, M. C. (2008). Mothering: Thinking is part of the job description: Application of cognitive views to understanding maladaptive parenting and doing intervention and prevention work. Journal of Applied Developmental Psychology, 29, 295-304. doi:10.1016/j.appdev.2008.04.009

Balge, K. A. \& Milner, J. S. (2000). Emotion recognition ability in mothers at high and low risk for child physical abuse. Child Abuse \& Neglect, 24, 1289-1298. doi:10.1016/S0145-2134(00)00188-5

Bargh, J. A. (1994). The four horsemen of automaticity: Awareness, intention, efficiency, and control in social cognition. In R. J. Wyer \& T. K. Srull (Eds.), Handbook of social cognition (pp. 1-40). Erlbaum, Inc.

Bargh, J. \& Chartrand, T. (2014). The mind in the middle: A practical guide to priming and automaticity research. In H. Reis \& C. Judd (Eds.), Handbook of research methods in social and personality psychology (2nd ed., pp. 311-344). Cambridge: Cambridge University Press. doi:10.1017/CBO9780511996481.017

Bauer, W. D. \& Twentyman, C. T. (1985). Abusing, neglectful, and comparison mothers' responses to child-related and non-child-related stressors. Journal of Consulting and Clinical Psychology, 53, 335-343. doi:10.1037/0022-006X.53.3.335

Beckerman, M., van Berkel, S. R., Mesman, J., \& Alink, L. R. A. (2018). Negative parental attributions mediate associations between risk factors and dysfunctional parenting: A replication and extension. Child Abuse \& Neglect, 81, 249-258.

doi:10.1016/j.chiabu.2018.05.001 
Bernard, K., Simons, R., \& Dozier, M. (2015). Effects of an attachment-based intervention on CPS-referred mothers' event-related potentials to children's emotions. Child Development, 86, 1673-1684. doi:10.1111/cdev.12418

Berthelot, N., Ensink, K., Bernazzani, O., Normandin, L., Luyten, P., \& Fonagy, P. (2015), Intergenerational transmission of attachment in abused and neglected mothers: The role of trauma-specific reflective functioning. Infant Mental Health Journal, 36, 200-212. doi:10.1002/imhj.21499

Besel, L. D. S. \& Yuille, J. C. (2010). Individual differences in empathy: The role of facial expression recognition. Personality and Individual Differences, 49, 107-112. doi:10.1016/j.paid.2010.03.013

Bolzani Dinehart, L. H., Messinger, D. S, Acosta, S. I., Cassel, T., Ambadar, Z., \& Cohn, J. (2005). Adult perceptions of positive and negative infant emotional expressions. Infancy, 8, 279-303. doi:10.1207/s15327078in0803_5

Branger, M. C. E., Emmen, R. A. G., Woudstra, M. J., Alink, L. R. A., \& Mesman, J. (2019). Context matters: Maternal and paternal sensitivity to infants in four settings. Journal of Family Psychology, 33, 851-856. doi:10.1037/fam0000562

Braungart-Rieker, J. M., Garwood, M. M., Powers, B. P., \& Wang, X. (2001). Parental sensitivity, infant affect, and affect regulation: predictors of later attachment. Child Development, 72, 252-270. doi:10.1111/1467-8624.00277

Bridgett, D. J., Kanya, M. J., Rutherford, H. J. V., \& Mayes, L. C. (2017). Maternal executive functioning as a mechanism in the intergenerational transmission of parenting: Preliminary evidence. Journal of Family Psychology, 31, 19-29. doi:10.1037/fam0000264

Calheiros, M. M., Silva, C. S., \& Magalhães, E. (2019). Development and validation of the Questionnaire of Child Maltreatment. Assessment. doi:10.1177/1073191119890030 


\section{EMOTION RECOGNITION IN CHILD ABUSE AND NEGLECT}

Calvo, M. G. \& Nummenmaa, L. (2016). Perceptual and affective mechanisms in facial expression recognition: An integrative review. Cognition and Emotion, 30, 1081-1106, doi:10.1080/02699931.2015.1049124

Camilo, C. \& Garrido, M. V. (2013). Desenho e avaliação de programas de desenvolvimento de competências parentais para pais negligentes: Uma revisão e reflexão [Design and evaluation of intervention programs for neglectful parents: A review and reflection]. Análise Psicológica, 31, 245-268. doi:10.14417/ap.697

Camilo, C., Garrido, M. V., \& Calheiros, M. M. (2016). Implicit measures of child abuse and neglect: A systematic review. Aggression and Violent Behavior, 29, 43-54. doi:10.1016/j.avb.2016.06.002

Camilo, C., Garrido, M. V., \& Calheiros, M. M (2020a). The social information processing model in child abuse and neglect: A meta-analytic review. Child Abuse \& Neglect. doi:10.1016/j.chiabu.2020.104666

Camilo, C., Garrido, M. V., \& Calheiros, M. M (2020b). Parental attitudes in child maltreatment. Journal of Interpersonal Violence. doi:10.1177/0886260520943724

Camilo, C., Garrido, M. V., Ferreira, M. B., \& Calheiros, M. M. (2019). How does mothering look like: A multidimensional approach to maternal cognitive representations. Journal of Family Issues, 40, 2528-2552. doi:10.1177/0192513X19860171

Camras, L.A., Ribordy, S., Hill, J., Martino, S., Spaccarelli, S., \& Stefani, R. (1988). Recognition and posing of emotional expressions by abused children and their mothers. Developmental Psychology, 24, 776-781. doi:10.1037/0012-1649.24.6.776

Chaffin, M., Silovsky, J. F., Funderburk, B., Valle, L. A., Brestan, E. V., Balachova, T., ..., \& Bonner, B. L. (2004). Parent-child interaction therapy with physically abusive parents: Efficacy for reducing future abuse reports. Journal of Consulting and Clinical Psychology, 72, 500-510. doi:10.1037/0022-006X.72.3.500. 


\section{EMOTION RECOGNITION IN CHILD ABUSE AND NEGLECT}

Crittenden, P. (1993). An information-processing perspective on the behavior of neglectful parents. Criminal Justice and Behavior, 20, 27-48.

doi:10.1177/0093854893020001004

Crittenden, P. M. (1999). Child neglect: Causes and contributors. In H. Dubowitz (Ed.), Neglected children: Research, practice, and policy (pp. 47-68). Thousand Oaks, CA: Sage Publications.

Crouch, J. L. \& Milner, J. S. (2005). The social information processing model of child physical abuse: A conceptual basis for prevention and intervention strategies. In K. Kendall-Tackett \& S. Giacomoni (Eds.), Child victimization: Maltreatment, bullying and dating violence, prevention and intervention. Kingston, NJ: Civic Research Institute.

Dadds, M. R., Mullins, M. J., McAllister, R. A., \& Atkinson, E. (2003). Attributions, affect, and behavior in abuse-risk mothers: A laboratory study. Child Abuse \& Neglect, 27, 21-45. doi:10.1016/S0145-2134(02)00510-0

De Paul, J. \& Guibert, M. (2008). Empathy and child neglect: A theoretical model. Child Abuse \& Neglect, 32, 1063-1071. doi:10.1016/j.chiabu.2008.03.003

DeOliveira, C. A., Moran, G., \& Pederson, D. R. (2005). Understanding the link between maternal adult attachment classifications and thoughts and feelings about emotions. Attachment \& Human Development, 7, 153-170. doi: 10.1080/14616730500135032

Dix, T. (1991). The affective organization of parenting: Adaptive and maladaptive processes. Psychological Bulletin, 110, 3-25. doi:10.1037/0033-2909.110.1.3

During, S. M. \& McMahon, R. J. (1991). Recognition of emotional facial expressions by abusive mothers and their children. Journal of Clinical Child Psychology, 20, 132-139. doi:10.1207/s15374424jccp2002_4 


\section{EMOTION RECOGNITION IN CHILD ABUSE AND NEGLECT}

Elfenbein, H. A. \& Ambady, N. (2002). Is there an in-group advantage in emotion recognition? Psychological Bulletin, 128, 243-249. doi:10.1037/0033-2909.128.2.243

Elliot, R., Campbell, L., Hunter, M., Cooper, G., Melville, J., McCabe, K., Newman, L. \& Loughland, C. (2014). When i look into my baby's eyes ... Infant emotion recognition by mothers with borderline personality disorder. Infant Mental Health Journal, 35, 2132. doi:10.1002/imhj.21426

Erhart, A., Dmitrieva, J., Blair, R. J., \& Kim, P. (2019). Intensity, not emotion: The role of poverty in emotion labeling ability in middle childhood. Journal of Experimental Child Psychology, 180, 131-140 doi:10.1016/j.jecp.2018.12.009

Éthier, L. S., Lemelin, J.P., \& Lacharité, C. (2004). A longitudinal study of the effects of chronic maltreatment on children's behavioral and emotional problems. Child Abuse \& Neglect, 28, 1265-1278. doi:10.1016/j.chiabu.2004.07.006

Farc, M. M., Crouch, J. L., Skowronski, J. J., \& Milner, J. S. (2008). Hostility ratings by parents at risk for child abuse: Impact of chronic and temporary schema activation. Child Abuse \& Neglect, 32, 177-193. doi:10.1016/j.chiabu.2007.06.001

Feshbach, N. D. \& Feshbach, S. (1982). Empathy training and the regulation of aggression: Potentialities and limitations. Academic Psychology Bulletin, 4, 399-413.

Ferrey, A. E., Santascoy, N., McCrory, E. J., Thompson-Booth, C., Mayes, L. C., \& Rutherford, H. J. V. (2016). Motivated attention and reward in parenting. Parenting, 16, 284-301. doi:10.1080/15295192.2016.1184928

Francis, K. J. \& Wolfe, D. A. (2008). Cognitive and emotional differences between abusive and non-abusive fathers. Child Abuse \& Neglect, 32, 1127-1137. doi:10.1016/j.chiabu.2008.05.007

Garrido, M.V., Lopes, D., Prada, M., Rodrigues, D., Jerónimo, R., \& Mourão, R. P. (2017). The many faces of a face: Comparing stills and videos of facial expressions in eight 
EMOTION RECOGNITION IN CHILD ABUSE AND NEGLECT

dimensions (SAVE database). Behavior Research Methods, 49, 1343-1360.

doi:10.3758/s13428-016-0790-5

Gilbert, R., Widom, C. S., Browne, K., Fergusson, D., Webb, E., \& Janson, S. (2009).

Burden and consequences of child maltreatment in high-income countries. Lancet, 373, 68-81. doi:10.1016/S0140-6736(08)61706-7

Halberstadt, A. G., Parker, A. E., \& Castro, V. L. (2013). Nonverbal communication: Developmental perspectives. In J. A. Hall \& M. L. Knapp (Eds.), Handbooks of communication science. Non-verbal communication, Vol. 2 (pp. 93-128). Berlin: De Gruyter Mouton.

Halberstadt, J., Winkielman, P., Niedenthal, P. M., \& Dalle, N. (2009). Emotional conception. Psychological Science, 20, 1254-1261. doi:10.1111/j.14679280.2009.02432.x

Hildyard, K. \& Wolfe, D. (2007). Cognitive processes associated with child neglect. Child Abuse \& Neglect, 31, 895-907. doi:10.1016/j.chiabu.2007.02.007

Jahoda, A., Pert, C., \& Trower, P. (2006). Socioemotional understanding and frequent aggression in people with mild to moderate intellectual disabilities. American Journal on Mental Retardation, 111, 77-89.doi:10.1352/08958017

Kantor, G. K., Holt, M., \& Straus, M. A. (2003). The parent-report Multidimensional Neglectful Behavior Scale. Unpublished manuscript, Family Research Laboratory, University of New Hampshire, Durham, NH.

Kaufman, J., Jones, B., Stieglitz, E., Vitulano, L., \& Mannarino. A. P. (1994). The use of multiple informants to assess children's maltreatment experiences. Journal of Family Violence, 9, 227-248. doi:10.1007/BF01531949 
Kim, K., Mennen, F., \& Trickett, P. K. (2017). Patterns and correlates of co-occurrence among multiple types of child maltreatment. Child \& Family Social Work, 22, 492502. doi:10.1111/cfs. 12268

Kotsou, I., Nelis, D., Grégoire, J., \& Mikolajczak, M. (2011). Emotional plasticity: Conditions and effects of improving emotional competence in adulthood. Journal of Applied Psychology, 96, 827-839. https://doi.org/10.1037/a0023047

Kropp, J. \& Haynes, M. (1987). Abusive and nonabusive mothers' ability to identify general and specific emotion signals of infants. Child Development, 58, 187-190. doi: $10.2307 / 1130300$

Larkin, K. T., Martin, R. R., \& McClain, S. E. (2002). Cynical hostility and the accuracy of decoding facial expressions of emotions. Journal of Behavioral Medicine, 25, 285-292. doi:10.1023/A:1015384812283

LoBue, V. \& Thrasher, C. (2015). The Child Affective Facial Expression (CAFE) set: Validity and reliability from untrained adults. Frontiers in Psychology, 5, 1532. doi:0.3389/fpsyg.2014.01532

Mammen, O., Kolko, D., \& Pilkonis, P. (2002). Negative affect and parental aggression in child physical abuse. Child Abuse \& Neglect, 26, 407-424. doi:10.1016/S01452134(02)00316-2

Mani, A., Mullainathan, S., Shafir, E., Zhao, J. (2013). Poverty impede cognitive function. Science, 341, 976-980. doi:10.1126/science.1238041

Mesman, J., Oster, H., \& Camras, L. (2012). Parental sensitivity to infant distress: what do discrete negative emotions have to do with it?. Attachment \& Human Development, 14, 337-348. doi:10.1080/14616734.2012.691649.

Milner, J. S. (1993). Social information processing and physical child abuse. Clinical Psychology Review, 13, 275-294. doi:10.1016/0272-7358(93)90024-G 


\section{EMOTION RECOGNITION IN CHILD ABUSE AND NEGLECT}

Milner, J. S. (2000). Social information processing and child physical abuse: Theory and research. In D. J. Hansen (Ed.), Nebraska symposium on motivation. Motivation and child maltreatment, Vol. 45 (pp. 39-84). Lincoln, NE: University of Nebraska Press.

Milner, J. (2003). Social information processing in high-risk and physically abusive parents. Child Abuse \& Neglect, 27, 7-20. doi:10.1016/S0145-2134(02)00506-9

Mulder, T. M., Kuiper, K. C., van der Put, C. E., Stams, G. J. M., \& Assink, M. (2018). Risk factors for child neglect: A meta-analytic review. Child Abuse \& Neglect, 77,198-210. doi:10.1016/j.chiabu.2018.01.006

Murray, L., Halligan, S., \& Cooper, P. J. (2010). Effects of postnatal depression on motherinfant interactions and child development. In G. Bremner \& T. Wachs (Eds.), Handbook of Infant Development ( $2^{\text {nd }}$ ed.; pp. 192-220). Oxford, U.K.: WileyBlackwell.

Mustillo, S. A., Dorsey, S., Conover, K., \& Burns, B. J. (2011). Parental depression and child outcomes: The mediating effects of abuse and neglect. Journal of Marriage and Family, 73, 164-180. doi:10.1111/j.1741-3737.2010.00796.x

National Scientific Council on the Developing Child (2012). The Science of Neglect: The Persistent Absence of Responsive Care Disrupts the Developing Brain-Working - Paper 12.

Neves, A. M. \& Lopes, D. (2013). A negligência parental no contexto do mau trato infantil: Um contributo para a delimitação e definição do conceito e sua medida no âmbito da prevenção primária [Parental neglect in the context of child maltreatment: Contributions for conceptual definition and measuriment in primary prevention]. In M. M. Calheiros \& M. V. Garrido (Eds.), Crianças em risco e perigo: Contextos, investigação e intervenção, Vol. 3 (pp. 145-190). Lisboa: Edições Sílabo. 


\section{EMOTION RECOGNITION IN CHILD ABUSE AND NEGLECT}

Nummenmaa, L. \& Calvo, M. G. (2015). Dissociation between recognition and detection advantage for facial expressions: A meta-analysis. Emotion, 15, 243-256. doi:10.1037/emo0000042

Palermo, R. \& Coltheart, M. (2004). Photographs of facial expression: Accuracy, response times, and ratings of intensity. Behavior Research Methods, Instruments, \& Computers, 36, 634-638. doi:10.3758/BF03206544

Pérez-Albéniz, A. \& De Paúl, J. (2006). Empathy and risk status for child physical abuse: The effects of an adult victim's pain cues and an adult victim's intent on aggression. Aggressive Behavior, 32, 421-432. doi:10.1002/ab.20142

Petty, R. E., Barden, J., \& Wheeler, S. C. (2002). The elaboration likelihood model of persuasion: Health promotions that yield sustained behavioral change. In R. J. DiClemente, R. A. Crosby, \& M. C. Kegler (Eds.), Emerging theories in health promotion practice and research (pp. 71-99). San Francisco: Jossey-Bass.

Pinderhughes, E. E., Nix, R., Foster, E. M., Jones, D., \& The Conduct Problems Prevention Research Group (2007). Parenting in context: impact of neighborhood poverty, residential stability, public services, social networks, and danger on parental behaviors. Journal of Marriage and the Family, 63, 941-953. doi:10.1111/j.17413737.2001.00941.x

Prada, M., Garrido, M. V., Camilo, C., \& Rodrigues, D. L. (2018). Subjective ratings and emotional recognition of children's facial expressions from the CAFE set. PLoS ONE 13(12): e0209644. doi:10.1371/journal.pone.0209644Raver et al., 2015

Rodriguez, C. M. (2010). Personal contextual characteristics and cognitions: Predicting child abuse potential and disciplinary style. Journal of Interpersonal Violence, 25, 315-335. doi:10.1177/0886260509334391 
EMOTION RECOGNITION IN CHILD ABUSE AND NEGLECT

Rodriguez, C. M. (2018). Predicting parent-child aggression risk: Cognitive factors and their interaction with anger. Journal of Interpersonal Violence, 33, 359 -378. doi:10.1177/0886260516629386

Rodriguez, C. M., Smith, T. L., \& Silvia, P. J. (2016). Parent-child aggression risk in expectant mothers and fathers: A multimethod theoretical approach. Journal of Child and Family Studies, 25, 3220-3235. doi:10.1007/s10826-016-0481-y

Rodriguez, C. M. \& Tucker, M.C. (2015). Predicting maternal physical child abuse risk beyond distress and social support: Additive role of cognitive processes. Journal of Child and Family Studies, 24, 1780-1790. doi:10.1007/s10826-014-9981-9

Saylik, R., Raman, E., \& Szameitat, A. J. (2018). Sex differences in emotion recognition and working memory tasks. Frontiers in Psychology, 9: 1072. doi:10.3389/fpsyg.2018.01072

Shah, A., Mullainathan, S., \& Shafir, E. (2012). Some consequences of having too little. Science, 338, 682-685. doi:10.1126/science.1222426

Sprengelmeyer, R., Perrett, D. I., Fagan, E. C., Cornwell, R. E., Lobmaier, J. S., Sprengelmeyer, A., ... Young, A. W. (2009). The cutest little baby face: A hormonal link to sensitivity to cuteness in infant faces. Psychological Science, 20, 149-154. doi:10.1111/j.1467-9280.2009.02272.x

Stith, M. S., Liu, T. L., Davies, C., Boykin, E. L., Alder, M. C., Harris, J. F., ... Dees, J. E. M. E. G. (2009). Risk factors in child maltreatment: A meta-analytic review of the literature. Aggression and Violent Behavior, 14, 13-29. doi:10.1016/j.avb.2006.03.006.

Stoltenborgh, M., Bakermans-Kranenburg, M. J., \& van Ijzendoorn, M. H. (2013). The neglect of child neglect: A meta-analytic review of the prevalence of neglect. Social Psychiatry and Psychiatric Epidemiology, 48, 345-355. doi:10.1007/s00127-012-0549$\mathrm{y}$ 
Strathearn, L., Li, J., Fonagy, P., \& Montague, P. R. (2008). What's in a smile? Maternal brain responses to infant facial cues. Pediatrics, 122, 40-51. doi:10.1542/peds.20071566

Straus, M. A., Hamby, S. L., Finkelhor, D., Moore, D. W., \& Runyan, D. (1998). Identification of child maltreatment with the parent-child Conflict Tactics Scales: Development and psychometric data for a national sample of American parents. Child Abuse \& Neglect, 22, 249-270. doi:10.1016/s0145-2134(97)00174-9

Swain, J. E. (2011). The human parental brain: In vivo neuroimaging. Progress in NeuroPsychopharmacology and Biological Psychiatry, 35, 1242-1254. doi:10.1016/j.pnpbp.2010.10.017

Tabachnick, B. G. \& Fidell, L. S. (2012). Using multivariate statistics (6th ed.). New York: Harper Collins.

Tracy, J. L. \& Robins, R. W. (2008). The automaticity of emotion recognition. Emotion, 8, 81-95. doi:10.1037/1528-3542.8.1.81

Unkelbach, C., Fiedler, K., Bayer, M., Stegmüller, M., \& Danner, D. (2008). Why positive information is processed faster: The density hypothesis. Journal of Personality and Social Psychology, 95, 36-49. doi:10.1037/0022-3514.95.1.36

van Nieuwenhuijzen, M. \& Vriens, A. (2012). (Social) cognitive skills and social information processing in children with mild to borderline intellectual disabilities. Research in Developmental Disabilities, 33, 426-434. doi:10.1016/j.ridd.2011.09.025.

Wagner, M. F., Milner, J. S., McCarthy, R. J., Crouch, J. L., McCanne, T. R., \& Skowronski, J. J. (2015). Facial emotion recognition accuracy and child physical abuse: An experiment and a meta-analysis. Psychology of Violence, 5, 154-162. doi:10.1037/a0036014 


\section{EMOTION RECOGNITION IN CHILD ABUSE AND NEGLECT}

Webb, R., Ayers, S., \& Endress, A. (2019). The City Infant Faces Database: A validated set of infant facial expressions. Behavior Research Methods, 50, 151-159. doi:10.3758/s13428-017-0859-9

Wechsler, D. (1997). Wechsler Adult Intelligence Scale (3rd ed.). San Antonio, TX: The Psychological Corporation. 